\title{
Liquid Storage Cylindrical Tank - Earthquake Analysis
}

\author{
Kamila Kotrasová ${ }^{1, *}$, and Eva Kormaníková ${ }^{1}$ \\ ${ }^{1}$ Department of Structural Mechanics, Institute of Structural Engineering, Faculty of Civil Engineering, The Technical University of \\ Kosice, Vysokoskolska 4, 04200 Kosice, Slovak Republic
}

\begin{abstract}
The ground-supported cylindrical tanks are used to store a variety of liquids. This paper provides the theoretical background for concrete containers fixed to rigid foundations due to earthquake events, describing of fluid hydrodynamic impulsive and convective (sloshing) effects on tank. Seismic responses: base shear, the bending moment and overturning moment are calculated by using the response spectra for Slovak republic risk region. As the examples is analysed the ground supported cylindrical concrete tanks for variable fluid filling.
\end{abstract}

\section{Introduction}

Industrial facilities contain a large number of constructions and structural components. Both building and non-building structures typically can be found in an industrial/chemical plant. Above ground pressurised tanks are typical examples of non-building structures of such sites.

Ground-supported storage tanks are built for storing a variety of liquids, e.g. water for drinking and firefighting, petroleum, oil, liquefied natural gas, chemical fluids, chemical and radioactive fluid wastes. Liquid storage containers are strategically very important structures, since they have vital uses in industries, nuclear power plants and are connected to public life. Seismic safely of liquid tanks is of considerable importance [1-7]. Water storage tanks should remain functional in the post earthquake period to ensure potable water supply to earthquake-affected regions and to cater the need for fighting demand. Industrial liquid tanks containing highly toxic and inflammable liquids and these tanks should not lose their contents during the earthquake. Satisfactory performance of tanks during strong ground shaking is crucial for there modern facilities. The seismic behaviour of liquid storage tanks is highly complex problem due to liquid-structure interaction [9, 13-19].

The liquid storage containers on basis of their structure with respect to ground can be classified into three categories: underground tanks, tank resting on grounds, overhead tanks - elevated tanks supported on standing. The Liquid storage tanks may be from the shape point of view following types: circular, rectangular, square, polygonal, spherical, conical, funnel tanks. I most cases the underground and on ground container are cylindrical or rectangular is shape but the shape of construction. Rectangular tanks are used to store small capacity of fluid. For economy these thanks should square in plan and their height should half of the side. Rectangular tanks are uneconomical for large capacities [8, 10-12].

\section{Cylindrical of fluid filled tank due to earthquake events}

A typical cylindrical tank is shown in Fig. 1. It essentially consists of a base plate rested on the ground and a vertically erected shell wall. Optionally, there may be a floating or fixed roof to protect the liquid content from the outside air, column(s) inside the tank to support the roof, ring girders to enhance the stiffness of the wall and to improve its stability, and anchorage along the border of the base plate to prevent uplift. For a broad tank with its diameter, and therefore the tank is generally left unanchored.

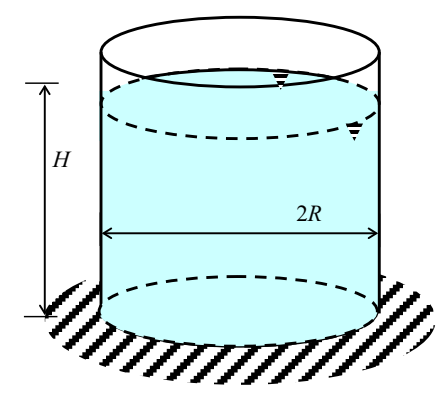

Fig. 1. Cylindrical tank.

Under the static condition, a cylindrical liquid storage tank is subjected to axisymmetric hydrostatic pressure caused by the liquid content acting radially outwards on the vertical tank shell wall. Hoop tensile force is developed in tank shell wall to withstand this pressure. In static design of a cylindrical tank, the required shell thickness of the shell wall is determined

* Corresponding author: author@,e-mail.org 
by the magnitude of this hoop tensile force. Under the static condition the base plate and the other parts of the tank structure bear no significant load and thus can be designed just to comply with the minimum structural requirements.

When a liquid storage tank is subjected to seismic load, vibrational motion of the liquid content is developed due to the ground excitation acting on it via the tank structure. The first one, defined as the "impulsive mode", consists of the liquid particles moving in unison with the motion of the tank structure. The second one, defined as the "convective mode" or usually called "sloshing", consists of the liquid particles near the free surface oscillating vertically. The resultant load effect of the liquid motion is generally represented by a total base shears and an total bending and overturning moments. In response to the hydrodynamic load, axial compressive and tensile stresses as well as additional hoop stress are developed in the tank shell wall. These stresses are asymmetric and much greater than that due to the hydrostatic pressure under the static condition. For an unanchored tank subjected to a sufficiently large resultant of total overturning moment, a portion of the base plate will separate from the support foundation. Accompanying with the base plate uplift, extensive deformations with significant out-of round distortion occur in the tank shell wall. The phenomenon is called the "uplift mechanism". The "uplift mechanism" is highly nonlinear to the applied load.

\section{Seismic analysis of fluid filled tank}

The problem of fluid-structure interaction is very important in case of fluid filled tanks. The motion of fluid in the tank is possible to define using the simple quasistatic model, in which the inertial forces are defined by hydrostatic and hydrodynamic pressure on the tank wall.

\subsection{Hydrodynamic pressure}

The seismic loads acting on wall and bottom of flexible cylindrical tanks (Figure 2) can be divided into the following components:

- the rigid impulsive component, caused by the inertia of the liquid, if the rigid tank moves together with the foundation,

- the convective load component, where the fluid vibrates in the rigid tank (sloshing),

- the impulsive flexible component tank shell of fluid (e.g. steel tanks).

The motion of the fluid contained in a rigid cylinder may by expressed as the sum of two separate contributions, which called "rigid" impulsive and convective, respectively. The "rigid" impulsive component satisfies exactly the boundary conditions at the walls and the bottom of the tank, but gives (incorrectly, due to the presence of the waves in the dynamic response) zero pressure at the original position of the free surface of the fluid in the static situation. The "convective" term does not alter those boundary conditions that are already satisfied, while fulfilling the correct equilibrium condition at the free surface. Use is made of a cylindrical coordinate system: $r, z, \theta$, with origin at the centre of the tank bottom and the radius are denoted by $H$ and $R$, respectively, $\rho$ is the mass density of the fluid, while $\xi=r / R$ is non-dimensional radius and $\zeta=z / H$ is non-dimensional coordinate.

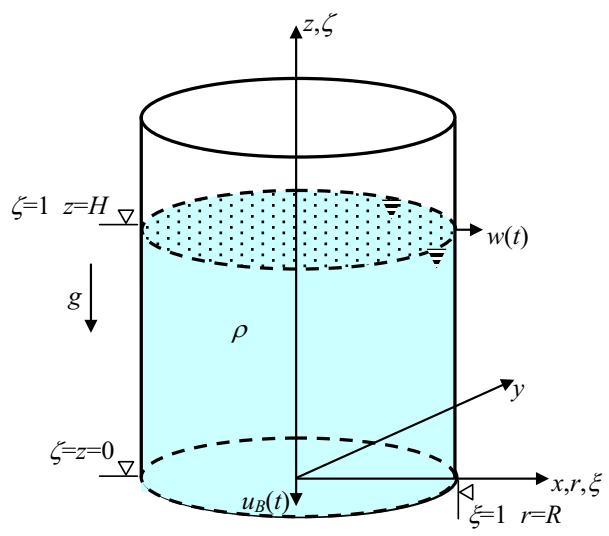

Fig. 2. Cylindrical tank.

\subsubsection{Rigid impulsive component}

The spatial-temporal variation of the "rigid" impulsive pressure is given by the expression

$$
p_{i}(\xi, \zeta, \theta, t)=C_{i}(\xi, \zeta) \rho H \cos \theta A_{g}(t)
$$

where

$$
C_{i}(\xi, \zeta)=2 \sum_{n=0}^{\infty} \frac{(-1)^{n}}{I_{1}^{\prime}\left(v_{n} / \gamma\right) v_{n}^{2}} \cos \left(v_{n} \zeta\right) I_{1}\left(\frac{v_{n}}{\gamma} \xi\right),
$$

$v_{n}=\pi \frac{2 n+1}{2}$ and $\gamma=H / R, I_{1}($.$) is the modified Bessel$ function of order 1 and $I_{1}^{\prime}($.$) is derivate can be expressed$ in terms of modified Bessel function of order 0 and 1 $I_{1}^{\prime}(x)=\frac{d I_{1}(x)}{d x}=I_{0}(x)-\frac{I_{1}(x)}{x}$. The function $C_{i}$ gives the distribution along the height of $p_{i} . \theta$ is angle of circumference, $\gamma=H / R$ is tank slenderness parameter, $A_{g}(t)$ is the horizontal ground acceleration time-history in free-field with peak value denoted by $a_{g}$ as a result of an equivalent single-degree-of-freedom system with a impulsive period $T_{i}$.

\subsubsection{Convective pressure component}

The spatial-temporal variation of the convective pressure component is given

$$
p_{c}(\xi, \zeta, \theta, t)=\rho \sum_{n=1}^{\infty} \psi_{n} \cos \left(v_{n} \gamma \zeta\right) J_{1}\left(v_{n} \xi\right) \cos \theta A_{c n}(t),
$$

where

$$
\psi_{n}=\frac{2 R}{\left(\lambda_{n}^{2}-1\right) J_{1}\left(\lambda_{n}\right) \cosh \left(\lambda_{n} \gamma\right)}
$$


$J_{1}$ is Bessel function of the first order, $\lambda_{n}$ are the roots of the first-order Bessel function of the first kind $\left(\lambda_{1}=1.8412 ; \lambda_{2}=5.3314 ; \lambda_{3}=8.5363, \lambda_{4}=11.71, \lambda_{5}=14.66\right.$ and $\left.\lambda_{5+i}=\lambda_{5}+5 i\right]$ for $i$ is given $\left.1,2, \ldots\right) . \quad A_{c n}(t)$ is acceleration time-history of the response of a single degree of freedom oscillator having a circular frequency $\omega_{c n}$ given by

$$
\omega_{c n}=\sqrt{\frac{g \lambda_{n} \tanh \left(\lambda_{n} \gamma\right)}{R}},
$$

so

$$
T_{c n}=\frac{2 \pi}{\sqrt{\frac{g \lambda_{n} \tanh \left(\lambda_{n} \gamma\right)}{R}}}
$$

and a $0.5 \%$ damping ratio appropriate for the sloshing of the fluid.

Only the first oscillating (sloshing) mode and frequency of the oscillating liquid $(n=1)$ needs to be considered in expression for design purposes.

$$
\omega_{c 1}=4.2 / \sqrt{R}
$$

which, for the usual values of $R$ yields periods of oscillation of the order of few seconds.

Only the first convective mode of vibration needs to be considered for practical applications in the analysis.

\subsubsection{Flexible component.}

It is normally unconservative to consider the tank as rigid. In flexible tanks the fluid pressure is usually expressed as the sum of tree contributions, referred to as: "rigid" impulsive, sloshing and flexible. The third satisfied the condition that the radial velocity of the fluid along the wall equals the deformation velocity of the tank wall, as well as the conditions of zero vertical velocity at the tank bottom and zero pressure at the free surface of the fluid. The dynamic coupling between the sloshing and the flexible components is very weak, due to the large differences between the frequencies of the sloshing motion and of the deformation of the wall, which allows determining the third component independently of the others.

The radial distribution of the flexible impulsive pressure on the tank bottom is qualitatively the same as for the rigid impulsive pressure. Assuming the modes as known, the flexible pressure distribution on the walls has the form

$$
p_{f}(\zeta, \theta, t)=\rho H \psi \cos \theta \sum_{n=1}^{\infty} \cos \left(v_{n} \zeta\right) A_{f n}(t)
$$

For a horizontal earthquake ground motion, the response of various SDOF systems may be calculated independently and then combined to give the base shear and overturning moment. The most tanks have the parameter tank slendernes $\gamma$, whereby $0.3<\gamma<3$. The parameter tank slendernes is given by relation $\gamma=H / L$, where $H$ is the filling height of fluid in the tank and $2 L$ is inside width of tank.

Values $m_{i}, h_{i}, h_{i}{ }^{*}, m_{c n}, h_{c n}$, and $h_{c n}{ }^{*}$ for rigid vertical circular tanks on ground, fixed to the foundation in Eurocode 8 - 4 [13] are shown in Fig. $7-10$.

\section{Mechanical model of fluid cylindrical filled tank due to earthquake events}

The dynamic analysis of a liquid - filled tank may be carried out using the concept of generalized single degree - of freedom (SDOF) systems representing the impulsive and convective modes of vibration of the tank - liquid system as shown in Fig. 3. For practical applications, only the first convective modes of vibration need to be considered in the analysis, mechanical model. The impulsive mass of liquid $m_{i}$ is rigidly attached to tank wall at height $h_{i}$. Similarly convective mass $m_{c n}$ is attached to the tank wall at height $h_{c n}$ by a spring of stiffness $k_{c n}$. The mass, height and natural period of each SDOF system are obtained by the methods described in [17].

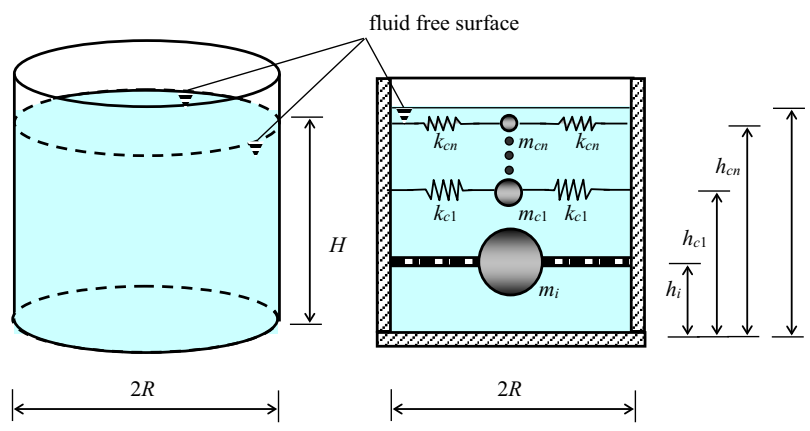

Fig. 3. Liquid-filled tank modeled by generalized single degree of freedom systems.

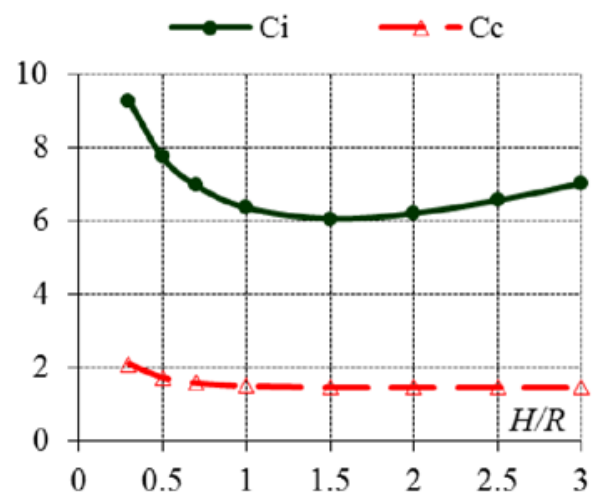

Fig. 4. Coefficients $C_{i}$ and $C_{c}$ as function of the tank slenderness parameter $\gamma=H / R$.

For a ground supported cylindrical tank, in which the wall is rigidly connected with the base slab, time period of impulse mode of vibration $T_{i}$ in [s] is given by

$$
T_{i}=C_{i} \frac{H \sqrt{\rho}}{\sqrt{t / R} \sqrt{E}}
$$


where $C_{i}$ is coefficient of time period for impulsive mode.

$$
T_{c}=C_{c} \sqrt{R}
$$

$C_{c}$ is coefficient of time period for convective mode. The values of $C_{i}, C_{c}$ are given from Fig. 4 .

The values of the masses $m_{i}$ and $m_{c}$ are given from Fig. 5.

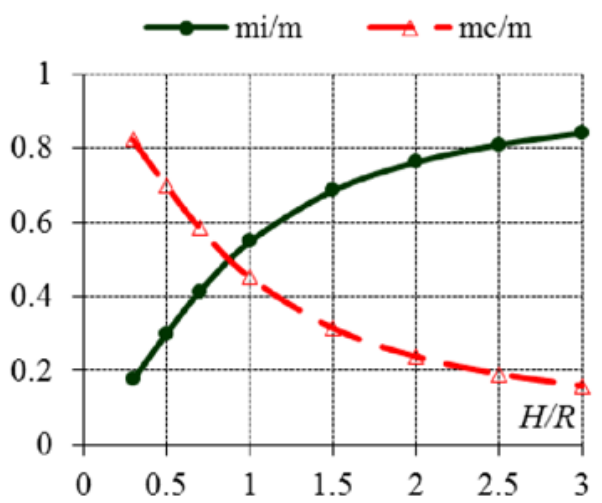

Fig. 5. Ratios $m_{i} / m$ and $m_{c} / m$ as function of the tank slenderness parameter $\gamma=H / R$.

The values of the corresponding heights of masses above the base $h_{i}, h_{c}$ are given from Fig. 8 and $h_{i}{ }^{*}, h_{c}{ }^{*}$ from Fig. 11.

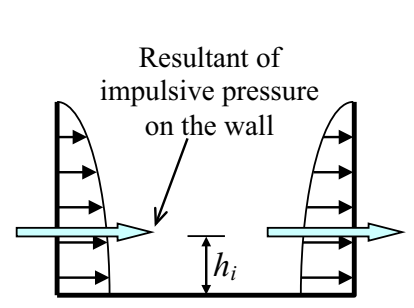

Resultant of impulsive pressure on the wall

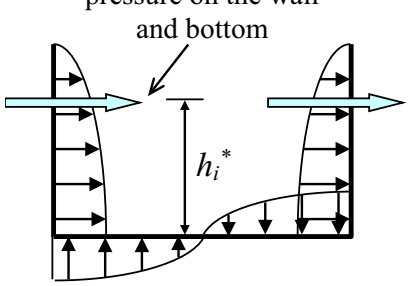

Fig. 6. Resultant of impulsive pressure on the wall.
Fig. 7. Resultant of impulsive pressure on the wall and bottom.

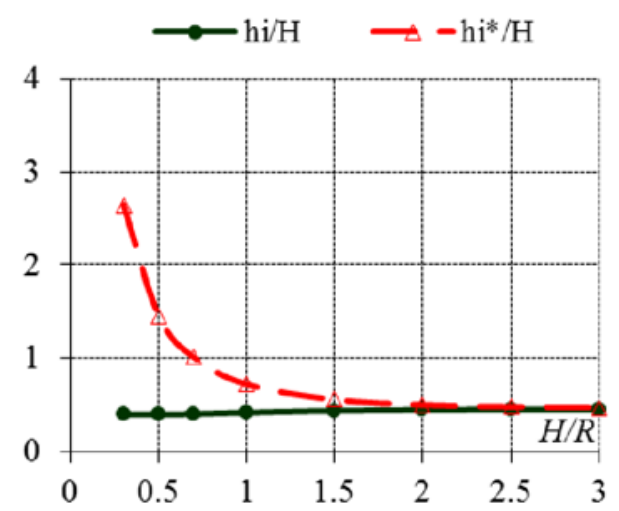

Fig. 8. Ratios $h_{i} / H$ and $h_{i}{ }^{*} / H$ as functions of the parameter tank slenderness $\gamma=H / R$.

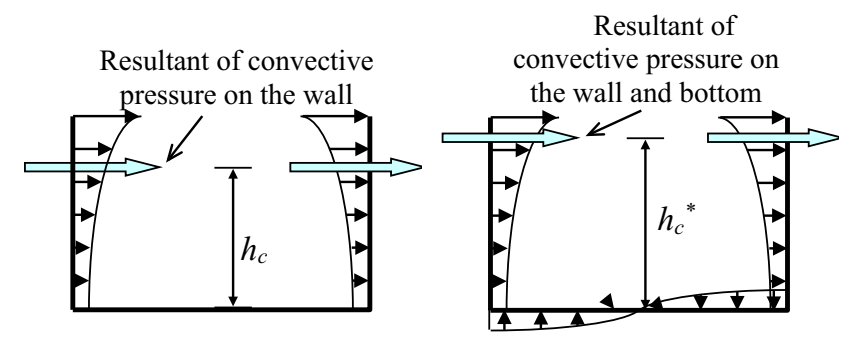

Fig. 9. Resultant of convective pressure on the wall.

Fig. 10. Resultant of convective pressure on the wall and bottom.

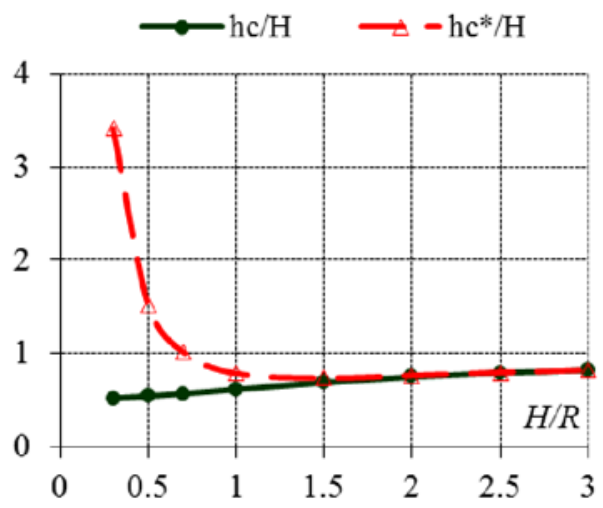

Fig. 11. Ratios $h_{c} / H$ and $h_{c}{ }^{*} / H$ as functions of the tank slenderness parameter $\gamma=H / R$.

Seismic coefficient $S_{e}(T)$ will be calculated separately for impulsive $S_{e}\left(T_{i}\right)$ and convective mode $S_{e}\left(T_{c}\right)$. The impulsive horizontal seismic coefficient is obtained from $2 \%$ damped elastic response spectrum for steel or pre-stressed concrete tanks and $5 \%$ damped elastic response spectrum for concrete and masonry tanks. The convective seismic coefficient is obtained from $0.5 \%$ damped elastic response spectrum [17].

The total base shear of ground supported tank at the bottom of the wall can be obtained by combining the overturning moment in impulsive and convective mode:

$$
V=\left(m_{i}+m_{w}+m_{r}\right) S_{e}\left(T_{i}\right)+\left(m_{c}\right) S_{e}\left(T_{c}\right) .
$$

The total base shear given by base shear in impulsive mode and base shear in convective mode at the bottom of base slab

$$
V^{*}=\left(m_{i}+m_{w}+m_{b}+m_{r}\right) S_{e}\left(T_{i}\right)+\left(m_{c}\right) S_{e}\left(T_{c}\right),
$$

where $m_{i}$ is impulsive mass of water, $m_{c}$ is convective mass of water, $m_{w}$ is mass of tank wall, $m_{b}$ is mass of base slab and $m_{r}$ is mass of roof of tank.

The base moment of ground supported tank at the bottom of the wall is given by base moment in impulsive mode and base moment in convective mode

$$
M=\left(m_{i} h_{i}+m_{w} h_{w}+m_{r} h_{r}\right) S_{e}\left(T_{i}\right)+\left(m_{c} h_{c}\right) S_{e}\left(T_{c}\right) .
$$

The total overturning moment can be obtained by combining the overturning moment in impulsive and 
convective mode to be used for checking the tank stability at the bottom of base slab/plate, and is given by

$$
\begin{aligned}
M^{*}= & \left(m_{i} h_{i}^{*}+m_{w} h_{w}^{*}+m_{r} h_{r}^{*}+m_{b}\left(t_{b} / 2\right)\right) S_{e}\left(T_{i}\right)+ \\
& +\left(m_{c} h_{c}^{*}\right) S_{e}\left(T_{c}\right) .
\end{aligned}
$$

\section{Numerical example and results}

A ground supported concrete cylindrical tank has inner dimensions: diameter $D=20 \mathrm{~m}$ and height $H=6.5 \mathrm{~m}$. Wall has uniform thickness $s=0.25 \mathrm{~m}$. The base slab thick $d$ is $0.4 \mathrm{~m}$. There is no roof slab on the tank. Tank is made from concrete, therefore, $E=3.40 \cdot 10^{7} \mathrm{kNm}^{-2}$, $\rho=2540 \mathrm{~kg} / \mathrm{m}^{3}$. The reservoir is filled with water $\left(\mathrm{H}_{2} \mathrm{O}\right)$, with density $\rho_{w}=1000 \mathrm{~kg} / \mathrm{m}^{3}$ to height $6.0 \mathrm{~m}$. We consider only horizontal seismic load only in horizontal direction. The elastic response spectrum was used for Slovakia.

A ground supported concrete cylindrical tank has capacity $1885 \mathrm{~m}^{3}$. The tank slenderness parameter given is by relation $\gamma=H / L$. In this case, where tank slenderness parameter is 0.3 , substantial amount of mass - $18 \%$ participates in impulsive and $82 \%$ participates in convective mode. The elastic response spectrums Elastic response spectrum is determined for Slovak republic region of seismic risk 2 . The impulsive spectral accelerations are obtained from a 5\% damped elastic response spectrum (for concrete tanks) and the convective spectral accelerations are obtained from a $0.5 \%$ damped elastic response spectrum.

The base shear above the tank bottom plate is 2,196 $\mathrm{kN}$, the base shear below the tank bottom plate 2,883 $\mathrm{kN}$, the total bending moment above the tank bottom plate $5,814 \mathrm{kNm}$, the total overturning moment below the tank bottom plate $15,769 \mathrm{kNm}$.

\section{Conclusions}

This paper presented the results from the hydrodynamic analysis of the reinforced concrete circular tank. Using of theoretical background for definition of impulsive and convective effects of fluid in liquid storage circular container was calculated the seismic response of tank due to earthquake even: the total base shears of the wall and the total base bending and overturning moments, immediately above and below the tank bottom plate, for full water filling of tank $6 \mathrm{~m}$. As ground motion was determined the elastic response spectrum for Slovak republic region of seismic risk 2 .

This work was supported by the Scientific Grant Agency of the Ministry of Education of Slovak Republic and the Slovak Academy of Sciences the project VEGA 1/0477/15 "Numerical analysis and modeling of interactive problems in multilayered composite structural members".

\section{References}

[1] A. Di Carluccio, G. Fabbrocino, E. Salzano, G. Manfredi, ICSV18 (2008), Beijing, China.

[2] N. Jendzelovsky, N., L. Balaz, Applied Mechanics and Materials. 617 (2014)

[3] K. Kralik, J. Kralik jr., Advanced Materials Research, 715 (2013)

[4] M. Krejsa, Z. Kala, S. Seitl, Procedia Engineering. 142 (2016)

[5] K. Kotrasová, I. Grajciar, E. Kormaníková, Journal of Vibration Engineering and Technologies. 3 (2015)

[6] M. Krejsa, P. Janas, V. Krejsa, International Journal of Mathematics and Computers in Simulation. 81 (2014)

[7] G. Lajcakova, J. Melcer Comunications : Scientific Letters of the University of Žilina. 133 (2011)

[8] R. Livaoğlu, A. Durmuş, Structural Engineering and Mechanics, 531 (2015)

[9] S. Medvecka, O. Ivankova Applied Mechanics and Materials 769 (2015)

[10] J. Melcer, Applied Mechanics and Materials, 486 (2014)

[11]J. Michel, M. Mihalikova, Acta Metallurgica Slovaca. 62 (2000)

[12] O. Sucharda, M. Pajak, T. Ponikiewski, P. Konecny Construction and Building Materials, 138 (2017)

[13] V. Valašková, J. Melcer, G. Lajčáková, Procedia Engineering. 111 (2015)

[14]B. Taraba, Z Michalec, V. Michalcova, T. Blejchar, M Bojko, M Kozubkova. Fuel. 118 (2014)

[15] K. Tvrdá, J. Dický, Journal of Civil Engineering. ISSN: 1336-9024

[16] M. Zmindak, I. Grajciar, Computers and Structures. 64 5-6 (1997)

[17] Eurocode 8 - Design of structure for earthquake resistance - Part. 4: Silos, tanks and pipelines. Januar 2006. 